\section{Characteristics of those paid below the National Minimum Wage}

- he National Minimum Wage (NMW) was introduced in April 1999 with two rates: one for those aged 18 to 21 (youth development rate) and one for those aged 22 and over (adult rate). A further rate for 16 to 17 -year-olds was introduced in October 2004. The level of the NMW for each age group has tended to increase each October, following recommendations from the Low Pay Commission. Table 1 outlines the NMW rates applicable in different years since its introduction in 1999.

The Annual Survey of Hours and Earnings (ASHE) is the National Statistic source for estimates of the number of jobs paying below the NMW. However, even though ASHE is the principle source for low-pay estimates, it is not the only official source. The Labour Force Survey (LFS) can also give estimates and is particularly important when looking at groups of workers affected by the NMW and their characteristics, which are not available from ASHE. The LFS carries far more personal information on the characteristics of lowpaid workers than ASHE, which only has limited personal data. Users (including the Low Pay Commission) are interested in where the low paid are concentrated and use the LFS extensively when examining the impact of NMW rate upratings on different groups of workers which cannot be identified in ASHE.

There is also a desire to know the number of workers who may be legitimately paid below the NMW under the minimum wage legislation. Those workers who undertake recognised trade apprenticeships or recognised training may be exempt from the NMW rates. Also, if an employee
Table 1

National Minimum Wage hourly rates, 1999 to 2008

United Kingdom

\begin{tabular}{lrrr}
\hline & 16 and 17-year-olds' rate ${ }^{1}$ & Youth development rate & Adult rate \\
\cline { 2 - 3 } & Age 16 and 17 & Age 18 to 21 & Age 22 and over \\
\hline April 1999 & - & 3.00 & 3.60 \\
October 2000 & - & 3.20 & 3.70 \\
October 2001 & - & 3.50 & 4.10 \\
October 2002 & - & 3.60 & 4.20 \\
October 2003 & - & 3.80 & 4.50 \\
& & & 4.85 \\
October 2004 & 3.00 & 4.10 & 5.05 \\
October 2005 & 3.00 & 4.25 & 5.35 \\
October 2006 & 3.30 & 4.45 & 5.52 \\
October 2007 & 3.40 & 4.60 & 5.73 \\
October 2008 & 3.53 & 4.77 & \\
\hline
\end{tabular}

Source: Low Pay Commission

1 Introduced in October 2004. 
receives accommodation with the job, employers are able to offset a certain amount of this against their employees' pay. Finally, piece-rate workers, whose productivity is below the piece-rate threshold, may also be legitimately paid less than the NMW under the law.

The LFS cannot provide accurate estimates of the number of individuals who fall into all of the categories exempt under the legislation and therefore may be legitimately paid below the NMW. For these reasons, it should be noted that the estimates of the number of jobs that pay below the NMW do not indicate the extent of non-compliance with the law.

There is also interest in the extent to which the LFS measures individuals as earning below the NMW when, in reality, they are earning at or above this rate. In certain instances, because of measurement error in the survey, individuals could be recorded as earning below the NMW when in practice they are paid at or above it.
This article firstly looks at the most recent estimates of the number of jobs paid below the NMW from the LFS, compares them with ASHE and looks at the main reasons for the difference. It then examines the key characteristics of those paid less than the NMW using the LFS, again comparing them with the ASHE estimates where appropriate. It goes on to look at the legitimate reasons for earning below the NMW and some of the problems associated with estimating the number of people in

\section{Box 1}

\section{Data sources and methodology}

\section{Annual Survey of Hours and Earnings}

ASHE is used to provide the National Statistics estimate of the number of jobs paid below the NMW. An employer is asked to provide detailed information on the hours and earnings of their employees, and is almost always derived from employers' pay records. The advantage of this is that it allows accurate estimates of earnings, which is why it gives the best estimate of the numbers of jobs paid below the NMW. A disadvantage of ASHE is that it only provides details on a limited range of personal characteristics excluding, for example, ethnicity and disability. Therefore, analysis looking at an individual's personal characteristics is limited.

\section{Labour Force Survey}

More information on personal characteristics is collected in the LFS which makes it useful for analyses of low pay by variables not collected in ASHE. The LFS is a household survey and results are published quarterly. Respondents are in the survey for five quarters (or waves) and earnings information is asked of those in waves 1 and 5 of the survey. These individuals are then weighted up to represent the total number of employees in the population.

An advantage of the LFS is that more in-depth analysis can be carried out using data from this survey, for example, on personal characteristics such as ethnicity and disability. One of its weaknesses is that it requires information on earnings and hours worked to be accurately recalled by the respondent. In addition, proxy responses are often accepted, where another member of the household responds on behalf of someone else, often without reference to any documentation such as pay slips. Another disadvantage is that the sample size in the LFS is much smaller than in ASHE and this inhibits the production of precise estimates, especially in the context of those earning below NMW, where the incidence is relatively low.

Among the earnings questions asked in the LFS are those about a respondent's basic hourly rate of pay, as well as gross weekly pay for the pay period and actual hours worked in the week preceding the interview. A derived hourly rate can be calculated by dividing gross weekly pay by the number of hours worked. The LFS also collects a stated hourly rate direct from respondents. In theory, the two measures should give the same estimates of hourly pay; in practice, they can differ by considerable amounts due to measurement error in the LFS. Skinner et al (2002) provides more detail. For a household survey such as the LFS, a stated rate is more accurate than a derived rate for measuring low pay, as less information is needed to be accurately recalled (see Ormerod and Ritchie 2007).

Although the stated rate is the preferred measure of low pay in the LFS, the main difficulty is that not all respondents give a stated hourly rate, which happens in about two-thirds of cases. To overcome this, the Office for National Statistics (ONS) developed an imputation technique with Southampton University. The values of hourly pay are imputed using nearest neighbour donation for those respondents who did not provide one. A summary of the methodology is as follows:

- a regression analysis with the log of the stated hourly rate as the dependent variable and a list of independent variables including derived hourly rate of pay, occupation, qualifications, age, gender and marital status is performed

- the cases are then split into separate groups for ages 16 to 17,18 to 21 and 22 and over to prevent donation across the national minimum wage bands

- within each age group, cases are sorted in order of their similarity to each other in terms of the regression model

- cases that do not have a stated hourly rate then take independent donor values from the five cases immediately above and the five cases immediately below them that have a stated hourly rate; each case therefore ends up with ten values of hourly rate

- a count is taken of each of the ten values and the average used to determine the number paid below the NMW

This type of nearest neighbour methodology is sometimes called a fractional imputation because an average is taken of ten imputed values, and in some cases only a fraction of the person may earn below the NMW. For example, if two donor values are below the NMW and eight are above, then 20 per cent of that person's weight will be included in the estimate of the number earning below the NMW. For further information on the imputation methodology, see Skinner et al (2002).

Estimates for industry sectors A to $\mathrm{O}$ only are used in low-pay analysis, so that the LFS estimates of low pay are brought more into line with estimates from ASHE. 
these categories. It then examines some other methodological reasons why some workers in the LFS are estimated to earn less than the NMW when in reality they may not. This analysis focuses on the LFS, but a similar piece of analysis undertaken by the Low Pay Commission seeks to investigate similar issues using ASHE; this is available on the Low Pay Commission's website. $^{1}$

\section{Number of jobs paid below the NMW}

Table 2 shows that, according to the April 2008 ASHE, there were 288,000 jobs paying less than the NMW (1.1 per cent of all UK employee jobs). This compares with the estimate from the LFS for April to June 2008 of 445,000 jobs paying below the NMW (1.7 per cent of all UK employee jobs). Table 2 also breaks down the estimate from the LFS into the number and proportion of first and second jobs paying below the NMW. There were 402,000 (1.6 per cent) main jobs paying less than the NMW and 44,000 (5.8 per cent) second jobs.

The differences between estimates of low pay from the LFS and ASHE have been well researched. The reasons for the discrepancy between the estimates from the two sources was explored by Ormerod and Ritchie (2007), where they demonstrated that the differences are mainly due to the source of earnings and hours information and the variables used to measure low pay. ASHE is an employer survey where the information is based on employer records, whereas the LFS is a household survey, with earnings and hours information provided by the respondent in the household. The preferred measure for low pay from the LFS is a stated hourly rate, but not all employees give one; ONS therefore has to estimate one for these respondents based on other

Table 2

\section{Estimates of the number and proportion of UK jobs paid below the NMW, 2008}

\begin{tabular}{lrrr}
\hline & $\begin{array}{r}\text { Jobs paid below NMW } \\
\text { (thousands) }\end{array}$ & $\begin{array}{r}\text { Total jobs } \\
\text { (thousands) }\end{array}$ & $\begin{array}{r}\text { Jobs paid below NMW } \\
\text { (percentages) }\end{array}$ \\
\hline Estimates from the LFS ${ }^{1}$ & & & \\
Main jobs & 402 & 25,342 & 1.6 \\
Second jobs & 44 & 773 & 5.8 \\
All jobs & 445 & 26,115 & 1.7
\end{tabular}

Estimates from $\mathrm{ASHE}^{1,2}$

All jobs

288

Notes:

1 LFS total jobs differ from ASHE total jobs because LFS low-pay analysis excludes industry Section P (private households with employed persons) and uses the earnings weight rather than the person weight to calculate main jobs.

2 These are the National Statistic for the number of jobs paid below the NMW.

Figure 1 information that is collected (see Box $\mathbf{1}$ for more details). The estimates from the LFS are less accurate than those from ASHE which uses a derived hourly rate from hours and earnings, which is more accurate when taken from employer records.

The fairly large difference between the estimates for 2008 from the two sources can be attributed to the different variables used in both sources, with the LFS using a stated hourly rate and ASHE using a derived (and more accurate) hourly rate to estimate the incidence of low pay. The stated rate in the LFS suffers from reporting error because respondents can round their responses when questioned (see Ormerod and Ritchie 2007 for further information on rounding). The tendency for respondents to round down to $£ 5.50$ in April to June 2008 can be seen from looking at the distribution of low-paid workers' hourly earnings. There is a large spike in the earnings distribution at $£ 5.50$ per hour where 137,000 (20 per cent) of the jobs paid below the NMW were reported by respondents to pay this amount (see Figure 1). It is not possible to tell how many of these jobs were actually paid this amount by their employer and

Hourly earnings in jobs held by employees aged 22 and over

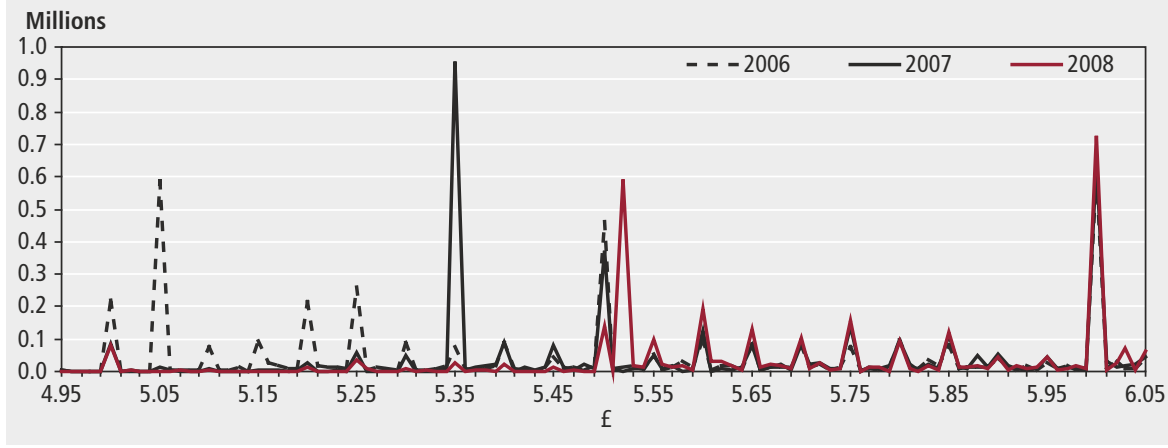

how much of this was due to respondents providing a rounded estimate when stating their hourly wage rate. However, the effect of rounding of responses does need to be taken into account when interpreting LFS estimates of low pay and in particular when comparing the levels from ASHE. Overall, ASHE provides more accurate estimates for hourly rates and therefore estimates of pay beneath the NMW, but analysis is limited by the small number of personal characteristics available, which is why the LFS is still useful for looking at the characteristics of low-paid workers.

\section{Characteristics of employees in jobs paid below the NMW}

Table 3 shows the number of employee jobs paid below the NMW, by age, sex and fulland part-time status according to the LFS, but also ASHE for comparison. As well as the number of jobs paid below the NMW, it provides the percentage in each category, for example, the proportion of jobs paid below the NMW that are filled by male and female employees. As a comparison, it provides similar information for all employee jobs in the UK labour market regardless of their level of pay. Finally, it provides the percentage of jobs paid below the NMW, by age, sex and full and parttime status.

There are not only differences in the total number of jobs paid below the NMW in the LFS compared with ASHE but also in the percentage shares for various characteristics. Users should be aware of these when using the LFS rather than ASHE, the preferred source of low-pay estimates.

\section{Age}

Estimates from the LFS show that a lower proportion of jobs paid below the NMW are filled by 16 to 17 and 18 to 21 -yearolds compared with estimates from ASHE. For example, for April to June 2008, the LFS indicates that 7 per cent of jobs that 
Table 3

Characteristics of employees in UK jobs paid below the NMW, 2008

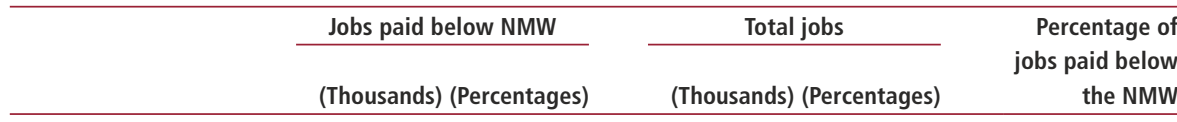

\section{Estimates from the LFS'}

Age

16 and 17-year-olds

18 to 21 -year-olds

22 and over

11
29

29

405

3
7
91

484
1,785
23,845

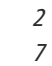

7

91

Sex

Men

Women

169

275

38

62

13,257

12,857

51

49

Full/part-time

Full-time

Part-time

154

291

35

65

18,914

7,200

72

28

Estimates from ASHE ${ }^{1}$

Age

16 and 17-year-olds

18 to 21 -year-olds

22 and over

17
47

16
78

422
1,830
23,942

2

1,830

7

Sex

Men

Women

103

185

36

64

13,258

12,937

51

49

\section{Full/part-time}

Full-time

Part-time

\section{2}

126

56
44

19,163

7,032

73

27 and April 2008 Annual Survey of Hours and Earnings

1 LFS total jobs differ from ASHE total jobs because LFS low-pay analysis excludes industry Section P (private households with employed persons) and uses the earnings weight rather than the person weight.

pay below the NMW were filled by 18 to 21-year-olds compared with ASHE, which estimates that, in April 2008, 16 per cent of jobs were filled by employees of that age.

Estimates from the LFS also show that a lower proportion of total jobs filled by 16 to 17 and 18 to 21 -year-olds are paid below the NMW than ASHE. For example, the LFS estimates that 2.3 per cent of all employee jobs filled by 16 and 17-year-olds were paid below the NMW whereas ASHE estimates in April 2008 that 3.9 per cent of such jobs were paid below the NMW.

The last column in Table 3 also shows that, in April to June 2008, the LFS estimates that 16 and 17 -year-olds are more likely than 18 to 21 -year-olds to be in jobs paying below the minimum wage ( 2.3 per cent compared with 1.6 per cent). Employees aged 22 and over (1.7 per cent) are more likely than 18 to 21-year-olds to be in jobs paying below the NMW but less likely than 16 and 17-yearolds. Table 4 shows that a similar difference was observed in 2007 . However, this pattern is not always reflected each year in the LFS. In 2005 and 2006, the LFS estimated that a lower proportion of 16 and 17-year-olds were in jobs paid below the NMW than 18 to 21-year-olds.

sizes and more accurate reporting by employers of pay rates.

\section{Sex}

The LFS estimates that a higher percentage of jobs filled by women are paid below the NMW compared with men (2.1 and 1.3 per cent, respectively) (Table 3). ASHE shows a similar picture, with 1.4 per cent of jobs filled by women being paid below the NMW compared with 0.8 per cent of jobs filled by men. Of the jobs paid below the NMW, the LFS estimated that 62 per cent of low-paid jobs were filled by women and 38 per cent by men in April to June 2008. ASHE estimated that 64 per cent were filled by women and 36 per cent by men in April 2008 (Table 3). Both sources estimate almost equal numbers of men and women employees in all jobs regardless of the level
Source: April to June 2008 Labour Force Survey

of pay. This illustrates that both the LFS and ASHE show that women are concentrated more in lower-paying jobs than men to a similar extent. Table 5 provides a four-year time series of the number and proportion of men and women in jobs paid below the NMW from the LFS compared with ASHE. It shows that both the number and percentages of men and women in jobs paid below the NMW are more consistent over time from ASHE than from the LFS.

\section{Full and part time}

The differences in the estimates of low pay for full- and part-time employees between the two surveys are larger than for age and sex. The LFS estimates that 65 per cent of jobs paid below the NMW in April to June 2008 are part-time jobs compared with ASHE that estimates only 44 per cent in April 2008 (Table 3). There are a couple of likely reasons for this difference. Firstly, the definitions of full and part time differ between ASHE and the LFS. In ASHE, part time is defined as any employee whose basic hours are 30 hours or less (less than 25 for a teacher) while in the LFS it is left to the respondent to decide whether someone considers themselves full or part time. Also it is known that ASHE undersamples part-time employees as it only covers PAYE-registered employees. Employees in these part-time low-paid jobs are less likely to be registered for PAYE as they may earn beneath the lower tax threshold and therefore employers have no need to register them. Also, the weighting methodology in ASHE does not post-stratify responses into full- and part-time calibration groups. Therefore, any undercoverage of part-time employees in the ASHE sample is not entirely corrected for by the weighting scheme, as it is in the LFS.

\section{Industry, occupation and region} Both ASHE and the LFS include earnings information by occupation, industry and region (of work and residence), so either of the surveys can be used to analyse low-paid workers by these categories. As with the variables considered above, the ASHE estimates should be used wherever possible, as they are derived from employer information and based on larger sample sizes and are therefore more accurate. The ASHE estimates for these variables are available from the ONS website. $^{2}$

Disability, ethnicity and qualifications Table 6 gives estimates of the number and proportion of jobs paid below the NMW by disability, ethnicity and qualifications. These 
Table 4

Number and proportion of UK jobs paid below the NMW: by age group, 2008

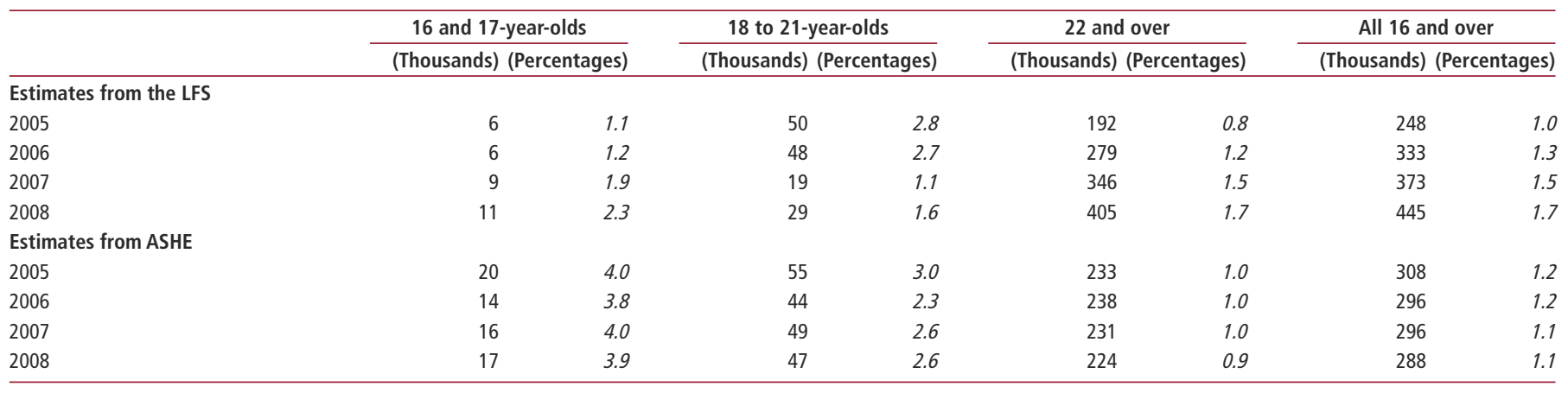

Source: April to June 2005 to 2008 Labour Force Survey and April 2005 to 2008 Annual Survey of Hours and Earnings

Table 5

Number and proportion of UK jobs estimated to be paying below the NMW: by sex, 2008

\begin{tabular}{|c|c|c|c|c|}
\hline & \multicolumn{2}{|c|}{ Men } & \multicolumn{2}{|c|}{ Women } \\
\hline & (Thousands) & (Percentages) & (Thousands) & (Percentages) \\
\hline \multicolumn{5}{|c|}{ Estimates from the LFS } \\
\hline 2005 & 65 & 0.5 & 182 & 1.5 \\
\hline 2006 & 111 & 0.9 & 222 & 1.8 \\
\hline 2007 & 137 & 1.0 & 236 & 1.9 \\
\hline 2008 & 169 & 1.3 & 275 & 2.1 \\
\hline \multicolumn{5}{|c|}{ Estimates from ASHE } \\
\hline 2005 & 129 & 1.0 & 179 & 1.4 \\
\hline 2006 & 118 & 0.9 & 178 & 1.4 \\
\hline 2007 & 120 & 0.9 & 176 & 1.4 \\
\hline 2008 & 103 & 0.8 & 185 & 1.4 \\
\hline
\end{tabular}

Source: Labour Force Survey Q2, 2005 to 2008 and Annual Survey of Hours and Earnings, April 2005 to 2008

Table 6

Characteristics of employees in UK jobs paid below the NMW, 2008

\begin{tabular}{|c|c|c|c|c|c|}
\hline & \multicolumn{2}{|c|}{ Jobs paid below NMW } & \multicolumn{2}{|c|}{ Total jobs } & \multirow{2}{*}{$\begin{array}{r}\text { Percentage of } \\
\text { jobs paid below } \\
\text { the NMW }\end{array}$} \\
\hline & \multicolumn{2}{|c|}{ (Thousands) (Percentages) } & \multicolumn{2}{|c|}{ (Thousands) (Percentages) } & \\
\hline \multicolumn{6}{|l|}{ Disability } \\
\hline Disabled & 83 & 19 & 3,510 & 13 & 2.4 \\
\hline Not disabled & 361 & 81 & 22,604 & 87 & 1.6 \\
\hline \multicolumn{6}{|l|}{ Ethnicity } \\
\hline White & 371 & 83 & 23,884 & 91 & 1.6 \\
\hline Asian/Asian British & 36 & 8 & 987 & 4 & 3.7 \\
\hline Black/Black British & 7 & 1 & 515 & 2 & 1.3 \\
\hline Chinese & 5 & 1 & 80 & 0 & 6.5 \\
\hline Mixed & 7 & 2 & 215 & 1 & 1.6 \\
\hline Other & 21 & 5 & 426 & 2 & 4.8 \\
\hline \multicolumn{6}{|l|}{ Qualifications } \\
\hline NVQ level 4 and above & 55 & 12 & 8,933 & 34 & 0.6 \\
\hline NVQ level 3 & 46 & 10 & 4,359 & 17 & 1.1 \\
\hline Trade apprenticeships & 9 & 2 & 1,036 & 4 & 0.9 \\
\hline NVQ level 2 & 90 & 20 & 4,160 & 16 & 2.2 \\
\hline Below NVQ level 2 & 88 & 20 & 3,561 & 14 & 2.5 \\
\hline Other qualifications & 54 & 12 & 2,023 & 8 & 2.7 \\
\hline No qualifications & 103 & 23 & 2,043 & 8 & 5.0 \\
\hline
\end{tabular}

Source: Labour Force Survey April to June 2008

characteristics are not available from ASHE and therefore this is where the LFS has to be used to provide estimates. In April to June 2008 , the proportion of jobs paying below the NMW filled by disabled employees was 19 per cent. This compares with 13 per cent of total jobs (regardless of pay level) filled by disabled people. Of all jobs filled by disabled employees, 2.4 per cent were paid below the NMW compared with 1.6 per cent of jobs filled by employees who were not disabled.
A lower share of low-paid jobs was filled by White employees than all employee jobs. In April to June 2008, 83 per cent of jobs that paid below the NMW were filled by White employees compared with 91 per cent of all jobs. The ethnic groups with the highest proportion of low-paid jobs in this period were Chinese (6.5 per cent), the 'Other' ethnic grouping (4.8 per cent) and Asian or Asian British (3.7 per cent). Black or Black British employees were least likely to be low paid, with 1.3 per cent of all their jobs being paid below the NMW. This is likely to be because this ethnic group is disproportionately concentrated in London, where wages are generally higher. The White and Mixed ethnic groups closely followed the Black and Black British employees, with 1.6 per cent of each group being paid below the NMW. It should be noted that estimates for ethnic minority groups are based on small sample sizes and therefore have larger sampling variability associated with them and this should be borne in mind when interpreting these estimates.

Perhaps not surprisingly, the majority of jobs paid below the NMW were filled with employees with low levels of qualifications. Over half ( 55 per cent) of jobs paid below the NMW were filled by employees with their highest qualification either 'below the NVQ level 2', 'other qualifications' or with 'no qualifications' at all. Only 30 per cent of all employee jobs (regardless of pay) were filled by employees with these levels of qualification. Only 12 per cent of jobs paid below the NMW were filled by employees with their highest qualification 'NVQ level 4 and above' compared with 34 per cent for all employee jobs in the economy.

\section{Exemption under the law - payment below the NMW for legitimate reasons}

As explained earlier in this article, workers may be exempt from NMW legislation or have a reduction in the NMW rate from 
their employer for different reasons. The analysis undertaken for this article looked to see to what extent the LFS could be used to measure how many of the employees estimated to be paid below the NMW were done so legitimately under the law. There were three main areas of interest:

- how many workers received commission/bonus payments, tips through the payroll or were on piece rates

- how many had accommodation provided by their employer, and

- how many were on recognised apprenticeships and training schemes

Where workers receive bonus/commission payments and tips through the payroll, their basic pay excluding these may be below the NMW but their total pay above; their employer is therefore still compliant with the law. Although the LFS does ask respondents whether their basic pay included any commission, tips or gratuity, it does not indicate the extent of these payments, so it is not possible to say how many of those who are paid below the NMW do so because they have reported their gross pay excluding these bonuses. The LFS also asks whether people's gross pay includes piecework payments, but again it does not ask how much of the pay is on this basis. Also, as the Low Pay Commission points out in their own analysis (referenced earlier in this article), the number of people in the LFS who report having bonus/commission payments, tips or piecework payments in the LFS is very small and sample sizes do not allow further disaggregation to give a reliable estimate of the number of low-paid workers being paid in this way.

There is an insufficient sample size in the LFS to produce a robust estimate of the number who receive accommodation tied to their job which would allow their employer to legitimately pay them below the NMW.

The LFS also includes a question on whether someone is doing a recognised trade apprenticeship. In April to June 2008, the LFS estimates that 3 per cent of employees in their main job (around $10,000)$ are paid below the NMW while currently undertaking a recognised trade apprenticeship. It should be noted that this estimate is based on a small sample size and therefore the sampling variability around the estimate is large. It is also not possible to determine from the LFS whether those receiving training are on recognised schemes, so it is not feasible to determine if this is a legitimate reason some are paid below the NMW.

\section{Methodological reasons for jobs being recorded as paying below the NMW}

As seen earlier with respondent rounding, the LFS has measurement errors when recording the amount that employees earn. There are also other methodological reasons why individuals could be recorded as earning below the NMW when in practice they are paid at or above the NMW.

\section{Imputation method}

ONS has made significant improvements over the last few years to the estimates of low pay from the LFS. The methodology used to estimate the number of jobs paying below the NMW is outlined in Box 1 . The use of the direct hourly rate question yields better estimates of hourly earnings than the derived hourly pay variable; the latter relies on dividing gross weekly pay in the pay period by usual hours of work, substantially overestimating the incidence of low pay. Studies have shown that using the stated (sometimes referred to as 'direct') hourly rate produces more reliable estimates of the low paid from the LFS than using the derived rate (Skinner et al 2002,

Dickens and Manning 2004). However, not all respondents state an hourly rate and therefore there is a missing data problem to overcome. The method that ONS uses to overcome this is a nearest neighbour imputation technique which uses a regression model to estimate an hourly rate for those that did not report one (Skinner et al 2002).

Although the imputation method provides an estimate of hourly pay for respondents who did not state an hourly rate of pay, there is the question of whether it may itself introduce bias in the estimation of low pay. The imputation method is based on the assumption that, where respondents do not provide a stated hourly rate of pay, this non-response is independent of their actual hourly rate of pay (which they did not state) even after conditioning on information that is available (for example, in this case their known derived hourly pay rate). This is known as the missing at random (MAR) assumption in the literature and the imputation process used in the estimation of low pay in the LFS is based on this assumption. However, the situation where individuals who are paid a higher rate of pay are less likely to have or know their hourly rate and therefore find it harder to provide an answer to this question could easily be envisaged. The extent to which the MAR assumption is violated will be reflected in the extent of overestimation in the number of low-paid jobs in the LFS. Durrant and Skinner (2006) show in their article that the nearest neighbour methods based on the MAR assumption may overestimate the level of low pay from the LFS by about 10 per cent. Put another way, when a method which is not dependent on the missing at random assumption was used, estimates of numbers paid below the NMW were 10 per cent lower.

Another, and perhaps more simplistic, way to look at whether the imputation method overestimates low pay, is to compare derived hourly pay rates at and above the NMW for those respondents who did and did not provide a stated hourly rate of pay (that is, reported versus imputed cases). Estimates based on respondents with a reported stated rate below the NMW and a derived rate equal to or above the NMW can be compared with estimates from respondents who have an imputed stated rate below the NMW and a derived rate at or above the NMW. If the MAR assumption holds, and the non-response to the stated hourly rate question is not dependent on the level of hourly pay, a similar proportion of employees with a reported and imputed hourly rate below the NMW may be expected to have a derived rate at or above the NMW.

In the April to June 2008 LFS, just under half (46 per cent) of employees in their main job (estimates for second jobs were not calculated) who had an imputed stated rate below the NMW had a derived hourly rate equal to or above the minimum wage. This compares with 27 per cent for those who reported a stated hourly rate below the NMW but had a derived hourly rate equal to or above the NMW, a difference of 19 percentage points. Given that those with an imputed rate only make up around 40 per cent of responses below the NMW, this equates to a potential upward bias of around 7 per cent in the estimate of people earning below the NMW. Similar estimates for 2007 (9 per cent) and 2006 (7 per cent) were also observed. These estimates are similar to Durrant and Skinner's estimate of overestimation of MAR-based methods. It could be argued that these should also be removed from the count of those paid below NMW from the LFS. However, this would rely on the further assumption that the stated hourly rate variable does not itself suffer from any measurement error (which again is a fairly strong assumption to 
make, given the findings presented earlier on the rounding effect and also the next section which looks at the measurement error resulting from the acceptance of proxy responses).

\section{Proxy responses}

Added to the issues surrounding the reporting of an hourly rate is the fact that, in around 30 per cent of cases, people respond to the earnings questions on behalf of someone else in the household. The estimates of the direct hourly rate that are reported by proxy respondents are less accurate than personal responses and are more likely to be rounded in the LFS (Ormerod and Ritchie 2007). Again, the question remains whether accepting these proxy responses when producing an estimate of low pay leads to any bias being introduced into the estimates. Previous research into the effect of proxy responses on overall earnings estimates suggests that derived hourly earnings in the LFS are understated by proxy respondents by between 2 and 13 per cent, depending on the type of proxy respondent (Wilkinson 1998). When proportions of proxy and personal responses that earn below the NMW are looked at separately, there is a difference in the estimates. In April to June 2008 , estimates based on personal responses indicate that 1.5 per cent of main employee jobs paid below the NMW compared with 1.7 per cent for proxy responses. If the assumption is made that personal responses are the best estimate of earnings, this difference equates to an overestimation of employees paid below the NMW of around 3 per cent in 2008. For 2006 and 2007, the upward bias is estimated to be larger, at around 11 and 9 per cent, respectively.

However, basing low-pay estimates purely on personal responses and excluding information by proxy can in itself introduce bias into the estimates. This is because individuals for whom someone else in the household reports on have different characteristics from those who provide a personal response. For example, respondents reported on by proxy are more likely to be younger and, as demonstrated earlier in this article, are more likely to be low paid. Another benefit of accepting information by proxy is that estimates are based on larger sample sizes.

\section{Conclusion}

The methodological reasons why the LFS may overestimate the extent of low pay, along with the issues in rounding of responses in the LFS, illustrate why there can be large differences between estimates from the LFS and ASHE. ASHE is the preferred measure of low pay in the UK, as it has a much larger sample and the earnings information obtained from employers is more accurate than information from householders in the LFS. However, as pointed out, ASHE only has limited information regarding employees' characteristics and the LFS therefore still has an important role in estimating low pay for the personal characteristics not available in ASHE. The limitations of the LFS and differences between the two surveys as collection instruments need to be borne in mind when using and interpreting low-pay estimates from both sources. It should also be noted that it is not possible to accurately estimate from the LFS how many of the employees in jobs below the NMW are legitimately paid below the NMW because of exemptions in the legislation and therefore estimates of these jobs are not a measure of non-compliance with the law.

\section{Notes}

1 See www.lowpay.gov.uk/lowpay/rep_ research_index.shtml

2 See www.statistics.gov.uk/statbase/ product.asp?vlnk=13272

\section{CONTACT}

四elmr@ons.gsi.gov.uk

\section{REFERENCES}

Dickens R and Manning A (2004) 'Has the national minimum wage reduced UK wage inequality?', Journal of the Royal Statistical Society A, 167, part 4, pp 613-26.

Durrant G and Skinner C (2006) 'Using data augmentation to correct for non-ignorable non-response when surrogate data are available: an application to the distribution of hourly pay', Journal of the Royal Statistical Society A, 169, part 3, pp 605-23.

Ormerod C and Ritchie F (2007) 'Issues in the measurement of low pay', Economic \& Labour Market Review 1(6), pp 37-45.

Skinner C, Stuttard N, Beissel-Durrant G and Jenkins J (2002) 'The measurement of low pay in the UK Labour Force Survey', Oxford Bulletin of Economics and Statistics 64, pp 633-52.

Wilkinson D (1998) 'Towards reconciliation of NES and LFS earnings data', Labour Market Trends 106(5), pp 223-31. 